\title{
Mentor-Mentee Program with Medical Students: A Successful Program with Ethical Considerations
}

Tin Tin Thein, ${ }^{1, *}$ Tun Aung, ${ }^{2}$ Aye Aye Wynn, ${ }^{1}$ Win Win Than, ${ }^{3}$ Mie Mie Sein, ${ }^{4}$ Nang Khin Mya, ${ }^{1}$ Fairrul Bin Masnah@ Kadir $^{5}$

\section{Abstract}

Background: Mentoring is the relationship of a guide or a teacher with another person/student augmenting his/her carrier growth, knowledge, skills, and experiences implemented by caring, sharing and helping hands. The aim of this paper is to highlight the mentoring, type of mentoring, how important of matching and consideration of ethical issue in mentoring program. Not missing these significant points, mentoring program could be successful in universities including medical faculty.

Methods: The SMART principles of specific, measurable, attainable, relevant, and timebound are essential to structure the matching between mentor and mentee. The rule of etiquette and ethical issues are crucial and beneficial for mentor mentee relationship. Clinical mentoring programs help to develop students' clinical skills and can increase interest in under-subscribed specialties. Positive mentoring plays a part in reversing the decline of academic medicine, by sparking interest through early research experiences.

Results: There is the short term goal which is to introduce an immediate support network for incoming students and the long term goal is to cultivate a mentoring culture to engage all strata of medical students and every faculty member. Medical students expressed that mentoring program is to provide counselling, develop professionalism, increase students' interest in research, and support them in their personal growth.

Conclusion: The goal of mentorship is to provide additional support to student or mentee by steering of the academic needs or social prerequisites to accelerate the personal and professional development of mentee with advice, guide and feed backs from the mentor.

Keywords: Mentoring, Mentor-mentee, Matching, Ethical issues, Medical students.
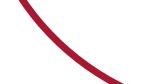

*Correspondence Email: dr.jasminetin@ums.edu.my

${ }^{I}$ Department of Pathology and Microbiology, Faculty of Medicine and Health Sciences,Universiti Malaysia Sabah

${ }^{2}$ Retired General Surgeon

${ }^{3}$ Department of Obstetics and Gynaecology, Faculty of Medicine and Health Sciences,Universiti Malaysia Sabah

${ }^{4}$ Department of Medical Education, Faculty of Medicine and Health Sciences, Universiti Malaysia Sabah

${ }^{5}$ Department of Emergency Medicine, Faculty of Medicine and Health Sciences,Universiti Malaysia Sabah

Received: 02/08/2021

Accepted: 23/09/2021 


\section{Introduction}

The plan of Ministry of Higher Education Malaysia is to enhance complete national and international quality of human capital (Abdullah, M.C., 2008). The student's orientated teaching and learning system in this era often affect them to face cumulative stress of university atmosphere and programs where adaptation is gloomy merely for them (Barber, J.E., 2010). There comes a mentor who is a guide as well as a role-model. The mentor will build trust, respect and interchange with mentee with regular meeting exchanging the ideas, improvement discussion to fulfill the goal. The mentor will detect the development problem and social recessions mainly long duration separation from parents or families amalgamated by learning stress. The benefits of mentees are developing strength and overcome the weakness, obtaining new ideas and thinking as well as exposure to new skills and knowledge (Jusiah, I., 2017). The aim of this paper is to highlight the mentoring, type of mentoring, how important of matching and especially consideration of ethical issue in mentoring program. Not missing these significant points, mentoring program could be successful in universities including medical faculty.

\section{Methods}

\section{Mentoring}

The mentoring is cost effective and efficient in resuming strength of attitude and to retain high potential student (University of People, 2021). The common objectives are: helping to develop leadership abilities, trying to get satisfactory outcomes accordingly, sharpening (honing) their capabilities resulting career development, having productive relationship among students and building of reputation of faculty outputs being the students (Arsad, N. et al., 2013).

In university, mentoring programs support resolute any social issues (economy and long term separation from family and loved ones). Next the program is offering to facilitate the acclimatization of student to faculty environment. This program is ready to help novices when they come after pre-university foundations to the eminent campus. Mentorship programs also provide students to improve with good career in next working places after graduation (University of People, 2021).

For career a mentor has two primary functions for the mentee. The career-related function establishes the coaching to develop professional status. The psychosocial function is a role model and support for the mentee. A mentee is a "learner" in mentoring relationships, regardless of the age or position of the mentor and mentee. Both functions raise the development of a profession and suitability in independent service in future (Bellevue, W.A., 2021).

Clinical mentoring programs help to develop students' clinical skills and can increase interest in under-subscribed specialties. Positive mentoring plays a part in reversing the decline of academic medicine, by sparking interest through early research experiences (Danielle, N. et al., 2019).

Medical Education Unit, UCMS and GTB Hospital, University of Delhi expressed a guide to mentoring medical students, in which program there are two short-term and longterm goals. The short term goal is to introduce an immediate support network for incoming students. The long term goal is to cultivate a mentoring culture at UCMS and GTBH that will engage all strata of students and every faculty member (Upreet, D. et al., 2021). 
There are three types of mentors: Mentors who have professional roles. They are the university staffs (often teaching staffs) and sometimes they may be administrative authorities who can assess career progress and support of any kind and shared the experience. Peer mentors: they do not influence the student, but support and they let the students learn actively. They do not overwhelm the mentees, but they support and share lessons learned for the progress of student's career and development. Subordinate mentors: they are not equivalent with above two mentors but they are working at a level to provide convenient assess for the novice students for evaluation or help once admitted in new atmosphere (Bellevue, W.A., 2021).

In addition to that, informal mentoring and formal mentoring are two more entities. The characteristics of formal mentoring which can reflect the program's effectiveness are:

(a) Program objectives, (b) Participants selection (c) Matching between mentor and mentee

(d) Training programs for both guide and students (e) Guide for meeting, and (f) Setting up a goal for the program. Structuring the good goals will follow SMART principles: specific, measurable, attainable, relevant, and time-bound (University of People., 2021).

\section{Matching}

Productive mentoring requires training of both mentor and mentee in view of understanding goals, role of participants and the process of the program. It means a good match for relationship. Sometimes the matching can face competency affairs, student background, style of studying and their needs. The consideration of matching may be by mentor himself or with administrative body depending upon the student (Bellevue, W.A. 2021).

A good match is important for a productive mentoring relationship. It is one of the critical parts of the program. A self-matching (mentor himself) is administratively light process, it allows mentees to select a particular mentor or they can submit their choice of three mentors. Matching with administrative body is applied for more structured programs such as a large group of new students at universities or new employees.

There are three steps for successful matching: 1).Develop a profile of data such as gender, college, interest and function, 2). Method of matching either self-matching or administrative matching, and 3). Intelligently match based on profiles (Bellevue, W.A. 2021).

Best practices of matching start with a solid profile for all participants (mentors and mentees). Development goals, specific interests, location, experiences, and preferences of matching are included in profile elements. For self-matching, participants might get the connection from the same previous employer, or the same college. Some prefer self-matching because if they know the about each other, a happy and productive mentoring outcome will be established. However, for more structured programs, such as new students at universities or groups of new corporate employees, administrative matching is usually applied. In medical university in Malaysia, administrative matching is being conducted and one mentor covers up to 10 mentees. There is monthly meeting with mentees where mentor supervise not only their academic progress but also take care of their physical and mental wellbeing. In intelligently match based on profile, improving match quality is appeared by using software and it can also save time (Bellevue, W.A. 2021). 


\section{Results}

\section{Etiquette and Ethics in Mentoring Program}

The quality of relationship may derive from added personal information to get professional growth and success of the program. The rule of etiquette is crucial and beneficial for mentor mentee relationship. In problematic episodes a mentor can support through the relationship to encourage for adjustment $t$ and ability to get up. The respect, reliability and calmness can create the environment for mentor to seek the needs of the student who will have good perspectives, good deeds and self-confident conduct of work.

The mentor and mentee should be aware of ethical issues. In an effort to facilitate the development of functional and successful mentor relationships, articulating the rules of etiquette for these encounters may prove beneficial for both mentors and mentees. Ethical principles are Beneficence and Non-maleficence, Fidelity and Responsibility, Integrity, Justice and Respect for People's Rights and Dignity. There is a question that is these ethical guidelines needed for mentor-mentee relationship? Actually, it needs to follow these guidelines.

\section{Discussion}

It is better to prepare for both mentor and mentee. The actual process of addressing beneficence and non-maleficence will be related to the purpose the mentoring. Both mentor and mentee must also be aware that mentoring is a mutual relationship and mutual respect. Each can benefit from the other over the course of the relationship. There are issues of workload and publication credit in a research context and confidentiality and navigation of internal political systems in organizational context, in which the benefit should go to both mentor and mentee.

A clarification process should be established regarding fidelity, responsibility and integrity to be able to develop a healthy and mature mentor relationship. If a point of conflict or confusion arises, each person should be willing to resolve that issue. A mentor is a guide or supervisor but mentor is not intended to dictate how to do something. Mentees follow the instructions of mentor however mentees him or herself takes responsibility of their duties and should not always depend on mentor.

A mentor should have a justice if a particular mentee will be chosen as opposed to other possible candidates. Respect for people's right and dignity highlight the personal differences between mentor and mentee which do not bias their interaction (American Psychological Association., 2012).

One review article of mentoring program for medical students expressed that mentoring program is to provide counselling, develop professionalism, increase students' interest in research, and support them in their personal growth. There are both one-to-one and group mentorships, established in the first two years of medical school and continuing through graduation. Other benefits are an increase in research productivity and improved medical school performance in general. Mentored students also rate their overall well-being as higher (Frei, E., et al., 2010). 


\section{Conclusion}

Including medical university, mentor programs offer a great place for mentors and mentees to learn and grow together. Successful mentorship leads to friendships with learning and support each other. The effective and productive mentor-mentee relationship has open communications and helping expectations, support and contact maintenance with honesty and friendship to get trust and respect. The mentor must participate creative activity and be innovative with guidance of etiquette and ethics. Thus mentorship programs are especially useful for new college students who want to get accustomed to the environment, culture and loving kindness of being in university.

\section{Conflicts of Interest}

The authors declare no conflicts of interest.

\section{References}

Abdullah, M.C. (2008). Contribution of Emotional Intelligence, Coping, and Social Support to Adjustment and Academic Achievement amongst Fresh Students in the University. Universiti Putra Malaysia. http://psasir.upm.edu.my/4903

American Psychological Association. (2012). Introduction to Mentoring: A Guide for Mentors and Mentees, Washington, DC 2002-4232. http://www.apa.org/education-career/grad/mentoring

Barber, J.E. (2010). An Examination of Happiness and Its Relationship to Community College Students' Coping Strategies and Academic Performance. Morgan State University. http://hdl.handle.net/11603/10658

Frei, E., Stamm, M., Buddeberg, F.B. (2010). Mentoring Programs for Medical Students: A Review of the PubMed Literature 2000-2008. BMC Med Educ., 10, 32(1-14). https://doi.org/10.1186/14726920-10-32

Jusiah, I., Melissa, E.S., Mohd. S.I. ((2017). Preliminary Review of Implementation Mentoring Program among Students in Public University in Kota Kinabalu. J. Adv. Rese. Soc. Behav. Sci. 8(1), 67-76. https://www.akademiabaru.com/doc/ARSBSV8_N1_P67_76.pdf

University of People. (2021). What Makes a College Mentoring Program Successful? California. https://www.uopeople.edu/blog/what-makes-a-college-mentoring-program-successful

Arsad, N., Kamal, N., Elias, S.N., Moubark, A.M., Ibrahim, A.A., Yusof, Y., Rahman, Ab., Mohammad, S., Husain, H., Ismail, M. (2015). Implementing the Use of E-Mentor Mentee and Mind Twister Program in Monitoring \& Improving the Student's Academic Performance. $J$. Eng. Sci. Technol., Special Issue 2 on UKM Teaching and Learning Congress 2013, 1-9. https://jestec.taylors.edu.my/Special\%20Issue\%20UKM\%20TLC\%202013_2/UKMTLC\%2020 13_6_2015_2_001_009.pdf

Bellevue, W.A. (2021). How to Start a High Impact Mentoring Program? CHRONUS. https://chronus.com/how-to-start-a-mentoring-program

Danielle, N., Shaista G., Joe, R. (2019). Medical Student Mentoring Programs: Current Insights. Advances in Medical Education and Practice, Adv. Med. Educ. Pract. 2019(10), 113-123. https://doi.org/10.2147/amep.s154974

Upreet, D., Kalra, O.P., Bhatia, A., Singh, N. (2021). A Guide to Mentoring Medical Students Medical Education Unit, UCMS and GTB Hospital, University of Delhi http://medicaleducationunit.yolasite.com/resources/A\%20Guide\%20to\%20Mentoring\%20Medic al\%20Students.pdf. 